Medical Botany

A Hand-book for Medical Men and All who are Concerned in the Use of Plants; Nutritionists, Dieticians, Pharmacists and Veterinarians. By Dr. Alexander Nelson. Pp. xi+544+16 plates. (Edinburgh: E. and S. Livingstone, L.td., 1951.) $30 s$, net.

HIS book sets out to give an account of the uses to which plants can be put by man as food and drugs and also of those plants which directly cause disease or injury to man.

The field covered is very wide and thus the amount of information which can be conveyed under any one heading is rather small. This results in the book being too generalized for the serious student of dietetics or nutrition or pharmacology and not elementary enough for the "members of the general public" mentioned in the introduction.

The most serious criticism of this book which can be offered is that the information contained is thrown together without any attempt at a critical assessment on the part of the author. This, together with a somewhat unkind use of the English language, makes recommendation impossible.

Two quotations must suffice to illustrate these points. On p. 209 , in the section on the broad bean, occurs the following sentence: "Apart from the use of garden beans in the young state, these seeds are used, almost exclusively, for stock food. A bean feast was not a feast of beans-the name has quite a different origin." (But we are not told what this different origin is, which is a pity ; though authorities do not seem clear about it. The term may have originated from the custom of having a feast on Twelfth Night when a cake with a bean buried in it was cut ; the person who received the slice containing the bean was elected 'bean-king'.)

Again, from p. 464 comes the following: "The probability of addiction following the use of opium and its derivatives has led to an increasing degree of control being exercised by governments on the growth of the poppy and the subsequent handling of the drug." Which sentence, taken at its face value, means that government controls nust be added to the factors limiting plant growth.

Finally, not all will applaud the classification of alcohol as a food while tea is considered as a drug. G. E. H. FoxoN

\section{Giordano Bruno}

His Life and Thought. With annotated translation of his work, On the Infinite Universe and Worlds. By Dorothea Waley Singer. Pp. $x i+389+9$ plates. (New York: Henry Schuman; London: Constable and Co., Ltd., 1950.) 40s, net.

IORDANO BRUNO the Nolan (1548?-1600) $\checkmark$ presents us with a problem of exceptional interest both for philosophers and historians of science. Scarcely less important is the place which he occupies in the development of ecclesiastical politics. As a personality, too, he is without rival among extreme psychological types, conditioned by a series of complex events. It is impossible to read this book without an intense sympathy for this "martyr of science", notwithstanding his infuriating follies.

Bruno's philosophy is essentially that of "an infinite universe with an infinity of worlds". Several consequences follow, of which his formulation at least cannot be regarded as particularly original.
His role was more that of a seer. But, oddly enough, his cosmology stemmed from two opposing roots, namely, those of Lucretius and of Cusanus. The former's thought was fundamerically mundane, the latter's subservient to his theology.

As the theme unfolds, we see something of Bruno's couple of years in Elizabethan London, of his rare periods of comparative repose, and of the gathering storm, culminating at the stake. Of special value is the annotated translation of his "On the Infinite Universe and Worlds". Like his great contemporaries, the humanist architects, Bruno found fascination in numbers, and in a certain species of transcendence.

Mrs. Singer has performed a great task-her erudition and restraint make the living and dying of her fulminating hero a stern reality in this twentieth century.

F. I. G. RAWLINS

\section{Synthetische Methoden der organischen Chemie}

Von W. Theilheimer. Repertorium 3. Pp. viii+412. (Basel and New York: S. Karger, 1949.) 40 Swiss francs.

7 HIS volume is the third of a series devoted to an attempt at the systematic recording of new synthetic methods in organic chemistry. Such a classification involves inherent difficulties which the author overcomes by the introduction of a novel system of reaction symbols representing processes such as addition, elimination, rearrangement and exchange, which are used in conjunction with a few empirical rules. For tha casual reader who may have neither the time, nor perhaps the inclination, to master this now technique, there is an alphabetical subject index which covers the first three volumes.

It is not clear on what basis the selection of material is based. It is sometimes difficult to decide with certainty whether a reaction is in fact new, and even more difficult to decide whether a given method is an improvement on a known process or not. In these cireumstances, the selection of the subjectmatter must become largely a matter of personal experience and opinion. The present volume refers mainly to publications of 1946 and 1947 and contains a high percentage of references to work published in the United States, which is intended to compensate in some measure for the paucity of American references in Vol. 2.

The volumes in this series are likely to be of some value to research workers and others engaged in preparative organic chemistry, in that they provide that type of information which might otherwise be difficult to locate. The inclusion of the "English Index Key" grossly underrates the intelligence of the average English-speaking reader.

\section{Advanced Organic Chemistry}

By Prof. Reynold C. Fuson. Pp. $x+669$. (New York : John Wiley and Sons, Inc.; London : Chapman and Hall, Ltd., 1950.) 64s. net.

HIS book departs from the usual structural method of depicting organic chemistry, with its use of homologous series and well-defined compound groupings (for example, amino-acids, steroids, etc.) as didactic stepping-stones. Instead, it concentrates on the reactions of the fundamental organic radical groupings in an attempt to delineate "the fundamental behavior patterns of organic compounds"; the emphasis throughout is on the practical, and theoretical concepts are kept to the bare essentials. This method of presentation combined with the 